\title{
United States of America
}

\section{"Monge v. Maya Magazines"}

Copyright Act, 17 U.S.C. $§ 107$ - Monge v. Maya Magazines, Inc.

Decision of the Court of Appeals for the Ninth Circuit 14 August 2012 - D.C. No. 2:09-cv-05077-R-SS

1. Although "news reporting" is listed as an example in the preamble to the fair use statute, it does not, per se, lead to a finding of fair use. Similarly, the exposure of truths in the public interest is insufficient to demonstrate fair use.

2. In order to determine whether news reporting constitutes fair use, it is necessary to take into consideration the degree of transformation occasioned by the use as well as its commercial nature.

3. Newsworthiness does not, however, lead to transformation. Furthermore, transformation is not given merely due to a difference in purpose.

4. The commercial use of copyrighted works is presumptively an unfair exploitation of the copyright owner's rights. It outweighs a minimal transformation, as is the case at hand.

5. The unpublished status of a work counter-balances the fact that it is merely marginally creative.

6. The commercial use of unpublished works amounting to a mere duplication of the original harms both the potential and actual markets for the sale of the work, thus undermining the copyright owner's rights. 